\title{
Occupant Injury Risk Assessment and Protective Measures in Frontal Collision of a Bus
}

\author{
Qian $\mathrm{PENG}^{1,2}$,Tingting $\mathrm{SUN}^{1}$, Pengpeng $\mathrm{ZHU}^{1}$, Fenggang $\mathrm{HAN}^{1,2}$, \\ Emmanuel Matsika ${ }^{3}$, Mark Robinson ${ }^{3}$
}

1. School of Mechanical and Automotive Engineering, Xiamen University of Technology, Xiamen, China;

2.Fujian Collaborative innovation centre for $R \& D$ of coach and special vehicle, Xiamen, China;

3. NewRail, School of Engineering Newcastle University, Newcastle, UK.

Qian PENG (corresponding author): Xiamen University of Technology, Xiamen 361024; +86 13600935038; pengqian603@163.com.

Tingting SUN: Xiamen University of Technology, Xiamen 361024, China; +86 17859731805; sun_tingting@qq.com.

Pengpeng ZHU: Xiamen University of Technology, Xiamen 361024, China; +86 17750597835; peterzhupp@163.com.

Fenggang HAN: Xiamen Vehicle Design \& Services Co., Ltd, Xiamen 361024, China; +86 13606017083; stariyhan@ 126.com.

Emmanuel Matsika: NewRail Research Hub, Stephenson Building, Claremont Road, Newcastle upon Tyne, NE1 7RU, UK; +44 1912088648; emmanuel.matsika@ncl.ac.uk. Mark Robinson: Newcastle University, Stephenson Building, Claremont Road, Newcastle Upon Tyne, NE1 7RU, UK; +44 1912086197; newrail@newcastle.ac.uk.

Dr. Qian PENG is an associate professor of School of Mechanical and Automotive Engineering, Xiamen University of Technology. Main research interests include crashworthiness, 
biomechanics and lightweight. He carries out research on China Project to improve vehicle safety.

Tingting SUN is a postgraduate student of Vehicle Engineering, School of Mechanical and Automotive Engineering, Xiamen University of Technology, majoring in crashworthiness. Pengpeng ZHU is a postgraduate student of Vehicle Engineering, School of Mechanical and Automotive Engineering, Xiamen University of Technology, majoring in crashworthiness. Fenggang HAN is a senior engineer of Xiamen University of Technology. His research fields are bus development project management and vehicle quality evaluation; CAE analysis and lightweight research on bus and components.

Dr. Emmanuel Matsika is a research associate at NewRail. He carries out research on EU Projects aimed at improving safety of passenger railway vehicles, and enhancing the performance of railway freight vehicles.

Mark Robinson is a professor of Rail Systems Engineering, School of Mechanical and Systems Engineering, Newcastle University since 2005 and Director of Newcastle Centre for Rail Research (NewRail) since 2004. Main research interests include the development and application of lightweight materials for rail vehicles and crashworthy composite structures. 


\section{Occupant Injury Risk Assessment and Protective Measures in Frontal Collision of a Bus}

Abstract: A significant issue worldwide is a bus frontal collision which can result in more than 10 fatalities per incident. The purpose of this study is to develop recommendations aimed at reducing occupant injury risk in such frontal collisions. To assess potential injuries, sled tests were carried out based on ECE R80. The influence of a lap belt on the kinematics and injury characteristics of the occupant was investigated. A LS-DYNA and MADYMO coupling method was used to study the influence of seat layout variables including seat pitch, height difference and back inclination angle on injury to different occupant body parts. By applying a combination of ECE R80 with FMVSS 208, the effectiveness and relevance of current test methods on occupant injury were evaluated. Subsequently, the protection measures were developed to reduce occupant injury risk. The results show that secondary collision with the front seat back can cause severe head and neck injuries. Although the lap belt can restrict the movement of the pelvis and lower limbs, the collision and relative slippage between the head and the front seat back can still cause a high neck bending moment. The study further reveals that seat layout variables should be design-specified to optimal values that minimize such injuries. Recommendations have been made on the development of government policy and industry standards aimed at improving the occupant injury risk in a frontal crash. It is strongly recommended to include injury severity based on head acceleration (not only HIC) and neck injury criteria.

Key words: Bus; Occupant injury risk; Frontal collision; injury criteria; LS DYNA and MADYMO; Secondary collision. 


\section{Introduction}

Although bus transport is considered as one of the safest and most reliable modes of transportation, statistics show that in China severe bus collisions predominantly result in a large number of fatalities making them the most serious type of motor vehicle traffic accidents [1]. From 2010 to 2015, bus frontal collisions occurred continuously in China, accounting for nearly $60 \%$ of all bus accidents. Among these frontal collisions, there are 17 severe accidents resulting in more than 10 fatalities per incident [2]. Secondary collision is the major cause of a large number of casualties in bus frontal collision, mainly including the contact between occupants and bus interiors or other occupants [3]. Of these casualties, about $50 \%$ are due to secondary collision between occupants and front seats [4]. The importance of this topic is reinforced by the fact that bus frontal collisions accounted for $42 \%$ of bus accident fatalities in the United States between 2000 and 2009 $[5]$.

In view of this serious situation, countries around the world have developed regulations on bus restraint system, such as the European ECE R80 [6], the United States' FMVSS 207[7] and Chinese Standard GB 13057-2014[8]. The regulations use the dynamic sled test to evaluate the occupant protection performance of the bus restraint system (seat belt/seat). As part of these global efforts, in 2015, the Chinese Ministry of Transportation initiated a programme to develop a National standard which includes structural strength requirements and test methods for bus frontal collision. 
Studies have been conducted to try and understand the bus design with respect to injury characteristics during a crash. Páez J [9] and Yongmao Fu[10] studied the injury characteristics in the frontal collision accidents of a bus. By applying sled tests, $\mathrm{H}$ Mitsuishi[5] analyzed the effects of different forms of seat belts on occupant head injuries; E Mayrhofer[11] evaluated the protective performance of a rear facing seats for an occupant during frontal collisions; Li[12] studied the protection effect of school bus frontal collision on child occupants; L Martínez[13] studied the effects of bus seats on occupant comfort and safety.

Due to the high level of customization characteristics of a bus, there are huge differences in seat layout, and types of seat structure and seat belts. These factors have different effects on the injury severity of an occupant in the frontal collision accidents. This makes standardization of test results obtained under regulations such as ECE R80 challenging. The ECE R80 assumes that the occupant is restrained using a lap belt. However, there still exist many classes of buses (particularly mass transit or commuter types) where occupant restraint is not a requirement. In other modes of transport, such as railways, seat belts are not standard practice. Therefore, compartmentalization has been applied as a means to minimize occupant injury severity [14-15]. In cases where a bus either does not use any belt, or uses a lap belt, design practices akin to compartmentalization would be useful in improving occupant safety protection.

With the aim of improving the way standards such as ECE R80 assess injuries; the purpose of this paper is to study the influence of seat layout and seat design 
characteristics on occupant injury characteristics in bus frontal collision. Sled tests were carried out based on ECE R80 to evaluate occupant kinematics behaviour when using a seat belt. Validated virtual tests were carried out by building a seat numerical model using finite element method (LS-DYNA) and Multi-Body (MADYMO) coupling. This was used to analyse the effects of seat pitch, height difference and back inclination on the kinematics response and occupant injury. The results provided the basis for developing measures for design and layout of seats aimed at improving occupant safety protection through improved standards.

\section{Sled Test}

\subsection{Test Introduction}

The aim of this activity was to carry out a sled collision test based on ECE R80. Two rows of two seats in transverse inline configuration were installed on the sled. The front row comprised of test seats and the rear row was the auxiliary seats. Each row had two seats fitted on a level sled, and had same shape and height. Two Hybrid III test dummies were placed on adjacent auxiliary seats (see Figure 1). The initial back angle of all the above seats was adjusted to $105^{\circ}$, and the seat pitch between the front and rear seats was $750 \mathrm{~mm}$. The acceleration pulse of the sled was generated by the hydraulic drive system. As shown in Figure, the acceleration curve was in the channel specified by ECE R80, and the test equivalent speed was $30 \mathrm{~km} / \mathrm{h}$. 
The experiment consisted of two sets of two sled test runs. The dummies of first set used a lap belt in order to record the injury values of dummy head, neck, chest, femur and tibia. The second set did not use any restraint device, so the occupant had a larger range of motion. Consequently, it was difficult to acquire the test data for dummy motion. However, it was possible to ascertain the seat reliability in meeting structural requirements because it did not fail. Failure of the seat would have resulted in the ejection of the dummy forwards.

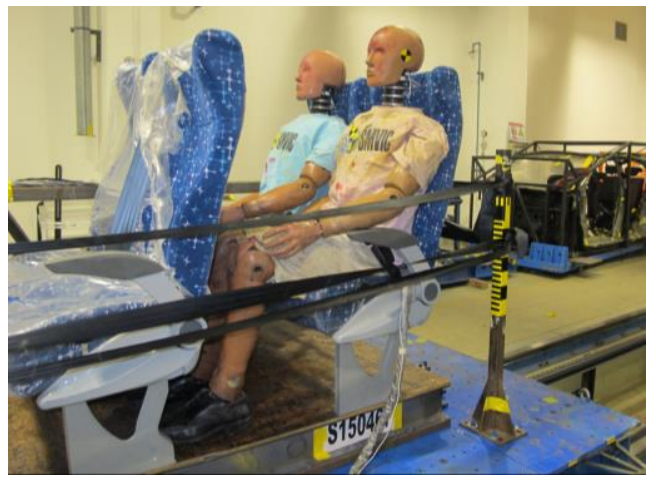

Figure 1: Illustration of test setup. The front row was test seats and the rear row was auxiliary seats with two dummies.

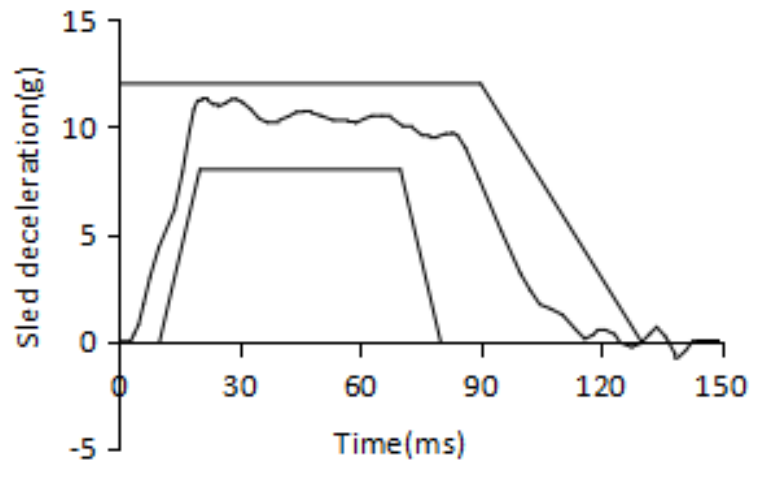

Figure 2: The crash test deceleration pulse at $30 \mathrm{~km} / \mathrm{h}$ 


\subsection{Dummy Motion Trajectory}

The collision sequence of the two sets is shown in Figure 3. The left side was tested with a lap belt, and the right side was without seat belt.

The dummy motion tendency in the two sets of experiments was similar at the initial stage. However, the trajectory of the occupants in the two sets showed a significant difference due to the restraint conditions. With the seat belt tightening, the upper torso of the occupant using lap seat belt experienced rotation about the pelvic region. The head collided with the front seat back and slipped along the chair face. On the other hand, the neck showed obvious 'backward' deformation (hyper flexion). For the occupant without a seat belt, after the occupant's knee made contact with the front seat back, after a time delay, the head collided with the front seat back under the impact of inertia. The body as a whole squeezed forward towards the front seat back, before tending into flight projectile motion.

These tests show that the lap seat belt is effective in restraining the forward movement of occupant. In the unrestrained state, the forward movement of occupant is restricted by the front seat, which provides the effect of compartmentalization. The above tests were carried out at $30 \mathrm{~km} / \mathrm{h}$. In real life accidents, the actual speed of the bus could be much higher. Without the use of seat belts, the occupant is faced with a high risk of unguided ejection. To minimize potential damage of the dummy, some researchers have used 
kinematics dummies [16]. Even though such dummies are not instrumented, they provide a good source of kinetics behaviour of an occupant.

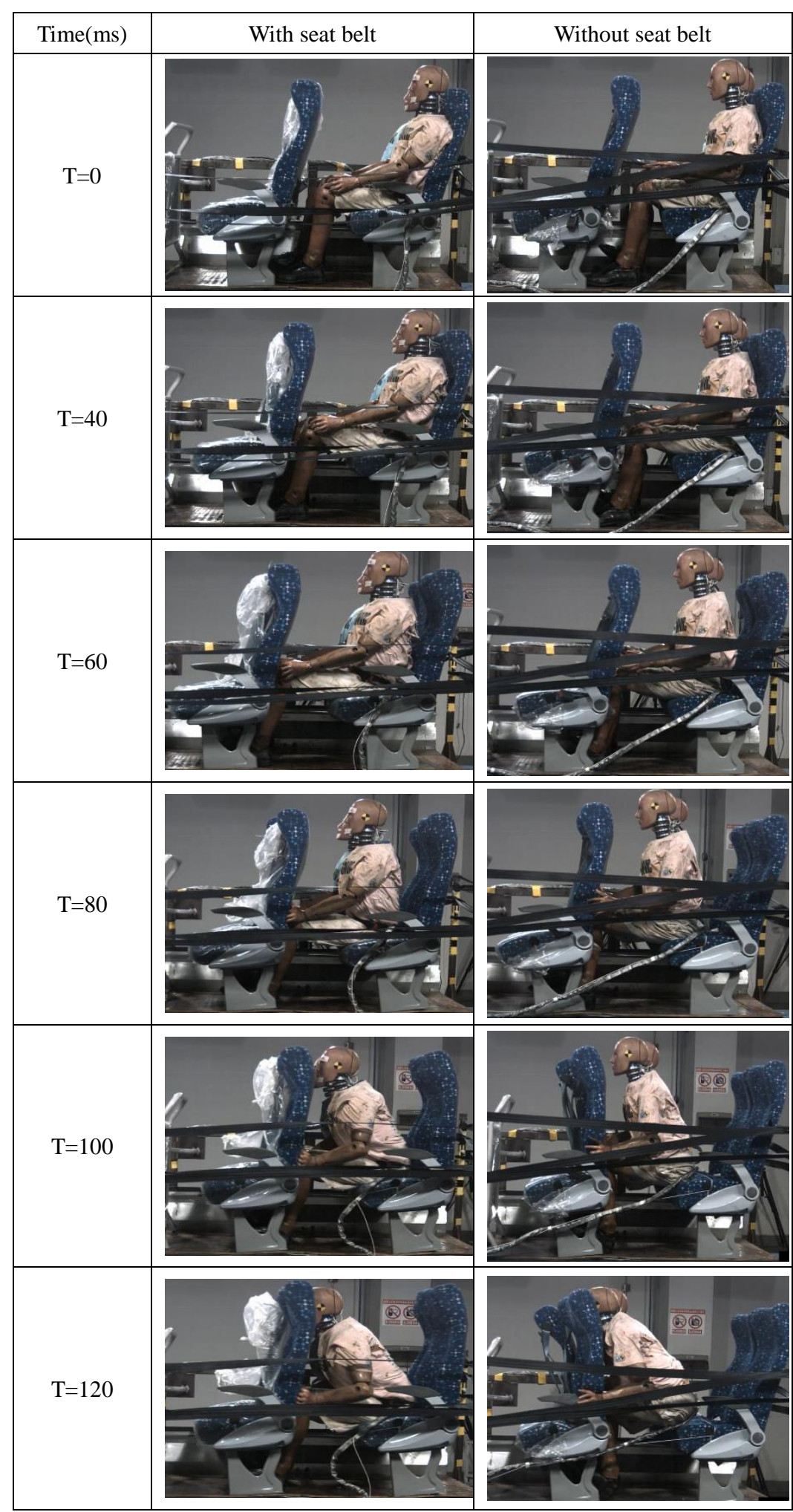




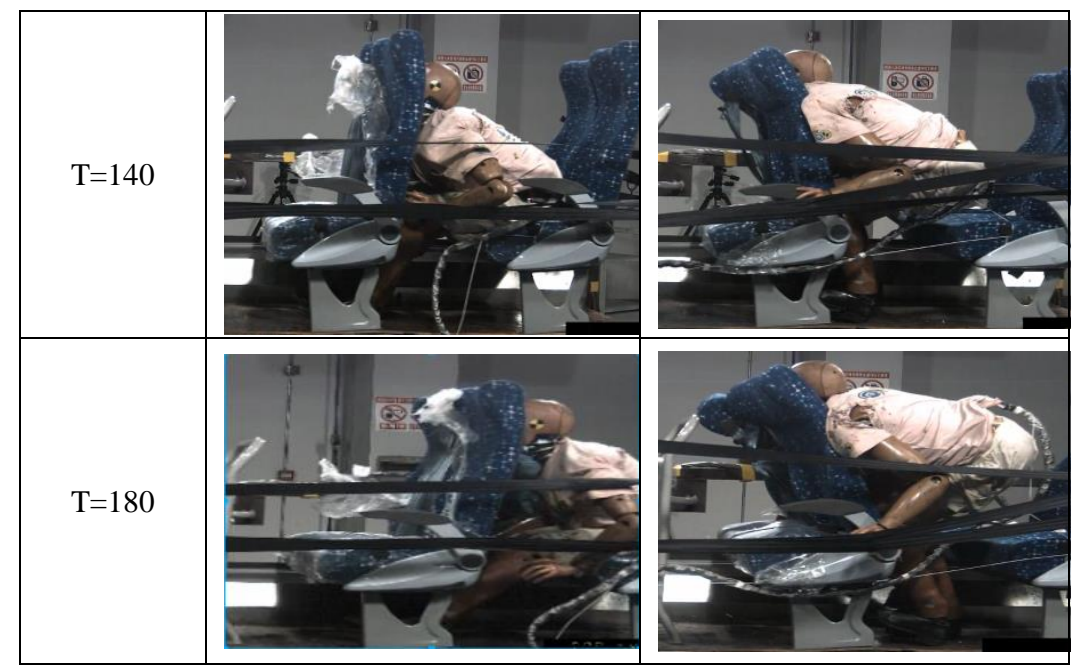

Figure 3: The dummy kinematics trajectory in the sled test. The left side was tested with a lap belt, and the right side was without seat belt.

\section{Numerical Model}

\subsection{Numerical Modelling}

As shown in Figure 4, a frontal collision numerical model is established by coupling LS-DYNA and MADYMO, including the sled, seat, seat belt and dummy. The finite element method is applied to establish the sled and seat. The geometric and material characteristics are obtained through actual measurement. To represent the occupants, a Hybrid III 50 percentile male dummy is employed, and a Multi-Body lap belt is used.

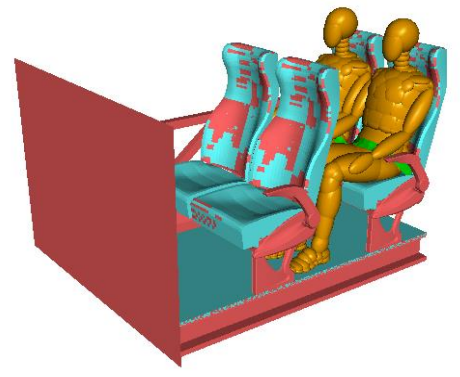

Figure 4: The numerical model of bus seat 


\subsection{Injury Criterion}

As shown in Table 1, the human injury criterion in this study is mainly based on the regulations ECE R80 and FMVSS208. The ECE R80 only assesses the head injury criterion (HIC), thorax acceptability criterion (ThAC) and femur acceptability criterion (FAC). However, this study will include additional criteria with the aim to evaluate the adequacy of the ECE R80 using the above parameters only. Hence, informed by the sled test kinematics, three additional parameters are investigated in this study in order to evaluate the occupant injury comprehensively. These are the head acceleration, neck injury value $\left(\mathrm{N}_{\mathrm{ij}}\right)$ and tibia index $(\mathrm{TI})$.

According to the Wayne State Tolerance Curve (WSTC) [17], the head injury risk can be judged by the rule that the head acceleration above $80 \mathrm{~g}$ cannot last more than $3 \mathrm{~ms}$ (Clip3ms). $\mathrm{N}_{\mathrm{ij}}$ in FMVSS208 [18] is defined as the comprehensive index under the combined action of axial tension and flexion of the neck in the process of deformation, and the limit value is 1.0. At the same time, the neck bending moment threshold is defined in FMVSS208 (i.e. the bending moment under the flexion position of the neck should not exceed 57Nm). Even though the evaluation index of lower limb injury is ignored in ECE R80, the UN R94 [19] includes it. Here, TI is defined as the weighted combination value of ankle bending moment and tibia axial loading. 
Table 1: Dummy injury region and criterion

\begin{tabular}{cccccccc}
\hline Region & Head & Chest & Femur & Head & \multicolumn{2}{c}{ Neck } & Tibia \\
\hline Parameter & HIC & ThAC & FAC & Head acceleration & $\mathrm{N}_{\mathrm{ij}}$ & $\mathrm{M}_{\mathrm{y}}$ & $\mathrm{TI}$ \\
Criterion & 500 & $30 \mathrm{~g}$ & $10 \mathrm{KN}$ & Clip3ms & 1.0 & $57 \mathrm{Nm}$ & 1.3 \\
\hline
\end{tabular}

\subsection{Numerical Model Validation}

The validity of the numerical model is assessed using occupant kinematics and injury evaluation. As shown in Figure 5, the sled and virtual simulation tests have high consistency for impact time, impact position, motion posture and front seat deformation.

As shown in Table 2, the dummy head, thorax and lower limbs injury values are within $10 \%$ of the differences between the sled test and the simulation. The above numerical model has an accuracy that provides a high level of confidence, and can therefore be used for subsequent parametric tests.

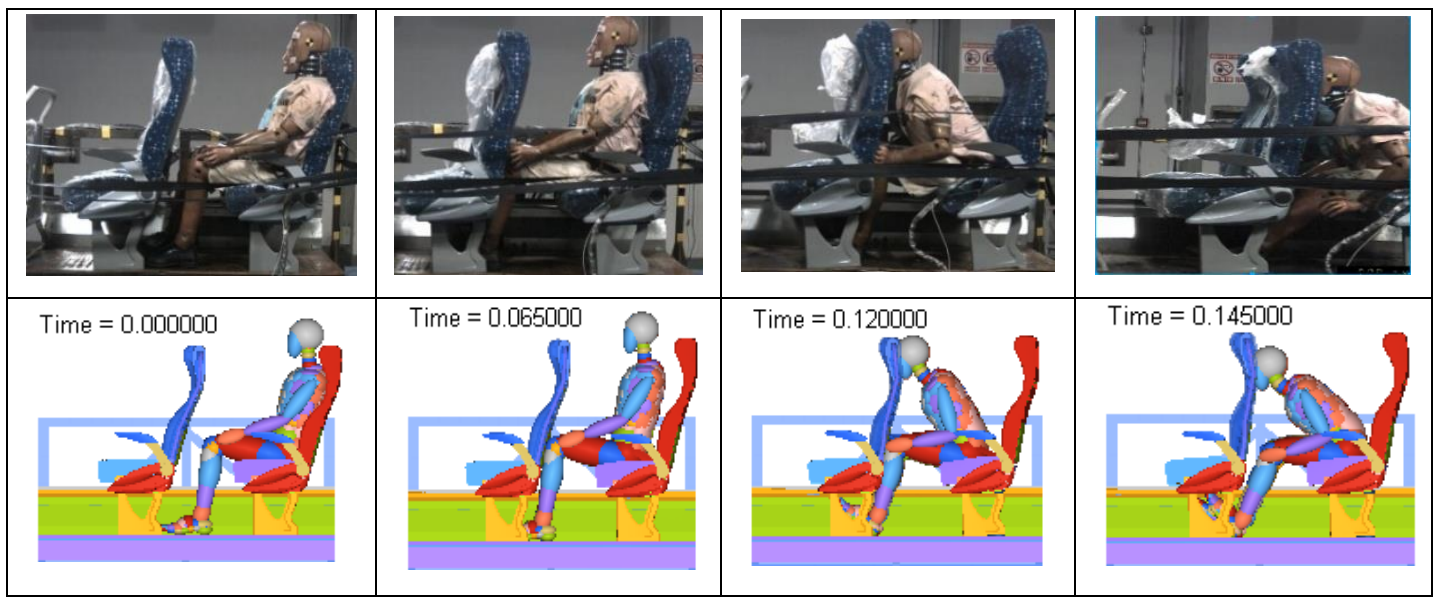

Figure 5: The kinematics of dummy showing a comparison between test and virtual simulation to verify the validity of simulation 
Table 2: Injury values of the sled test and virtual simulation

\begin{tabular}{cccccccccc}
\hline & \multirow{2}{*}{$\mathrm{HIC}$} & \multirow{2}{*}{$\mathrm{ThAC}(\mathrm{g})$} & \multicolumn{2}{c}{$\mathrm{FAC}(\mathrm{KN})$} & \multirow{2}{*}{$\mathrm{N}_{\mathrm{ij}}$} & & \multirow{2}{*}{$\mathrm{M}_{\mathrm{y}}$} & \multicolumn{2}{c}{$\mathrm{TI}(\mathrm{KN})$} \\
\cline { 5 - 6 } & & & $\mathrm{L}$ & $\mathrm{R}$ & & & $\mathrm{L}$ & $\mathrm{R}$ \\
\hline Sled Test & 405 & 18.83 & 2.09 & 2.06 & 0.51 & 65 & 0.65 & 0.63 \\
Virtual Simulation & 423 & 19.61 & 1.95 & 1.89 & 0.46 & 59 & 0.62 & 0.59 \\
Discrepancy & $4.44 \%$ & $4.14 \%$ & $6.69 \%$ & $8.25 \%$ & $9.80 \%$ & $9.23 \%$ & $4.61 \%$ & $0.63 \%$ \\
\hline
\end{tabular}

\subsection{Simulation Analysis Scheme}

According to the occupant injury outcomes in different seat layouts, some suggestions for bus interior layouts are developed. These can also provide a reference for the safety standard of a bus structure to improve its passive safety, and strengthen the passenger protection. As part of a parametric study, three factors are considered. These are the seat pitch (D), height difference (A) and back inclination $(\alpha)$. Illustrated in Figure 6 is the seat. The seat pitch refers to the horizontal distance between a line on the front seat back and the adjacent rear seat at the level above the datum plane (the horizontal surface of heel and floor contact points), located $620 \mathrm{~mm}$ above the reference floor. The height difference refers to the distance between the top of front seat and that of rear seat. When the rear seat height is greater than the front seat height, it is positive, otherwise it is negative. The inclination angle refers to the angle between the centre line of the seating cushion and the centre line of the backrest.

The values of the research parameters are shown in Table 3. According to ECE R80 and GB13057-2014, the prescribed seat pitch is $750 \mathrm{~mm}$. Therefore, two pitch values lower and three values higher were included in the parametric study, with a step difference of 
$50 \mathrm{~mm}$. Therefore, the following six pitches were selected: $650 \mathrm{~mm}, 700 \mathrm{~mm}, 750 \mathrm{~mm}$, $800 \mathrm{~mm}, 850 \mathrm{~mm}$ and $900 \mathrm{~mm}$. The front and rear row seats are arranged on the same level, so in order to study the influence of seat height difference on occupant injury, the paper sets up five points: $-200 \mathrm{~mm},-100 \mathrm{~mm}, 0,100 \mathrm{~mm}$ and $200 \mathrm{~mm}$. According to the standard QC-T 633-2000[20] the angle of inclination should be from $95^{\circ}$ to $105^{\circ}$. In addition, the regulation of the range of angle adjustment should not exceed $20^{\circ}$. Therefore, in this study the selected rear seat back angles were $95^{\circ}, 100^{\circ}, 105^{\circ}, 110^{\circ}$ and $115^{\circ}$, adjusting the dummy posture respectively in the existing model.

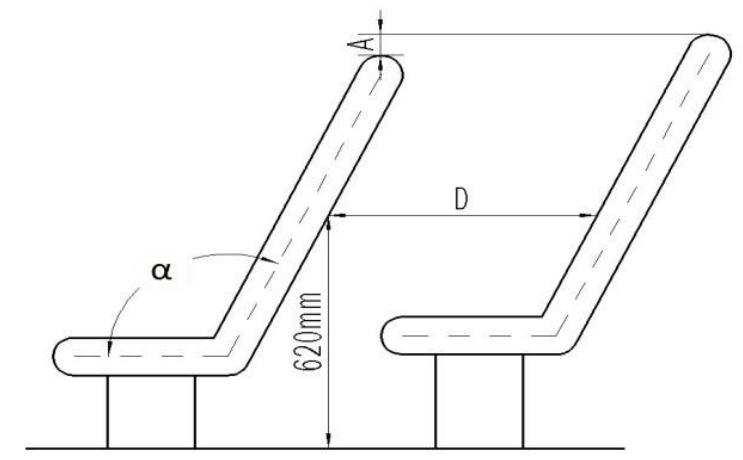

Figure 6: The seat configuration illustration showing the definition of seat pitch, high difference and back inclination angle.

Table 3: Simulation variables

\begin{tabular}{ccccccc}
\hline & No.1 & No.2 & No.3 & No.4 & No.5 & N.6 \\
\hline D & $650 \mathrm{~mm}$ & $700 \mathrm{~mm}$ & $750 \mathrm{~mm}$ & $800 \mathrm{~mm}$ & $850 \mathrm{~mm}$ & $900 \mathrm{~mm}$ \\
A & $-200 \mathrm{~mm}$ & $-100 \mathrm{~mm}$ & $0 \mathrm{~mm}$ & $100 \mathrm{~mm}$ & $200 \mathrm{~mm}$ & \\
$\alpha$ & $95^{\circ}$ & $100^{\circ}$ & $105^{\circ}$ & $110^{\circ}$ & $115^{\circ}$ & \\
\hline
\end{tabular}




\section{Results}

\subsection{Influence of Seat pitch on the Kinematics and Injury Characteristics}

Figure 7 shows the kinematics response of the belted occupant with a varying seat pitch.

The initial kinematics is similar for all scenarios until a body part makes contact with the front seat back. As the distance travelled before contact is different for each test case, the time and position of contact between tibia, knee, head and front seat back are variable. It is noteworthy that for $\mathrm{D} \leq 800 \mathrm{~mm}$, the knee contacts the front seat back first. Thereafter, the upper body rotates about the pelvis axis until the head collides with the seat. For $\mathrm{D} \geq$ $850 \mathrm{~mm}$, the knee does not contact the front seat due to the initially large distance. The tendency, however, is for the tibia to be loaded in bending about a point near the centre of the shin. Nevertheless, similarly to the cases where $\mathrm{D} \leq 800 \mathrm{~mm}$, the upper body rotates about the pelvis axis until the head collides with the seat.

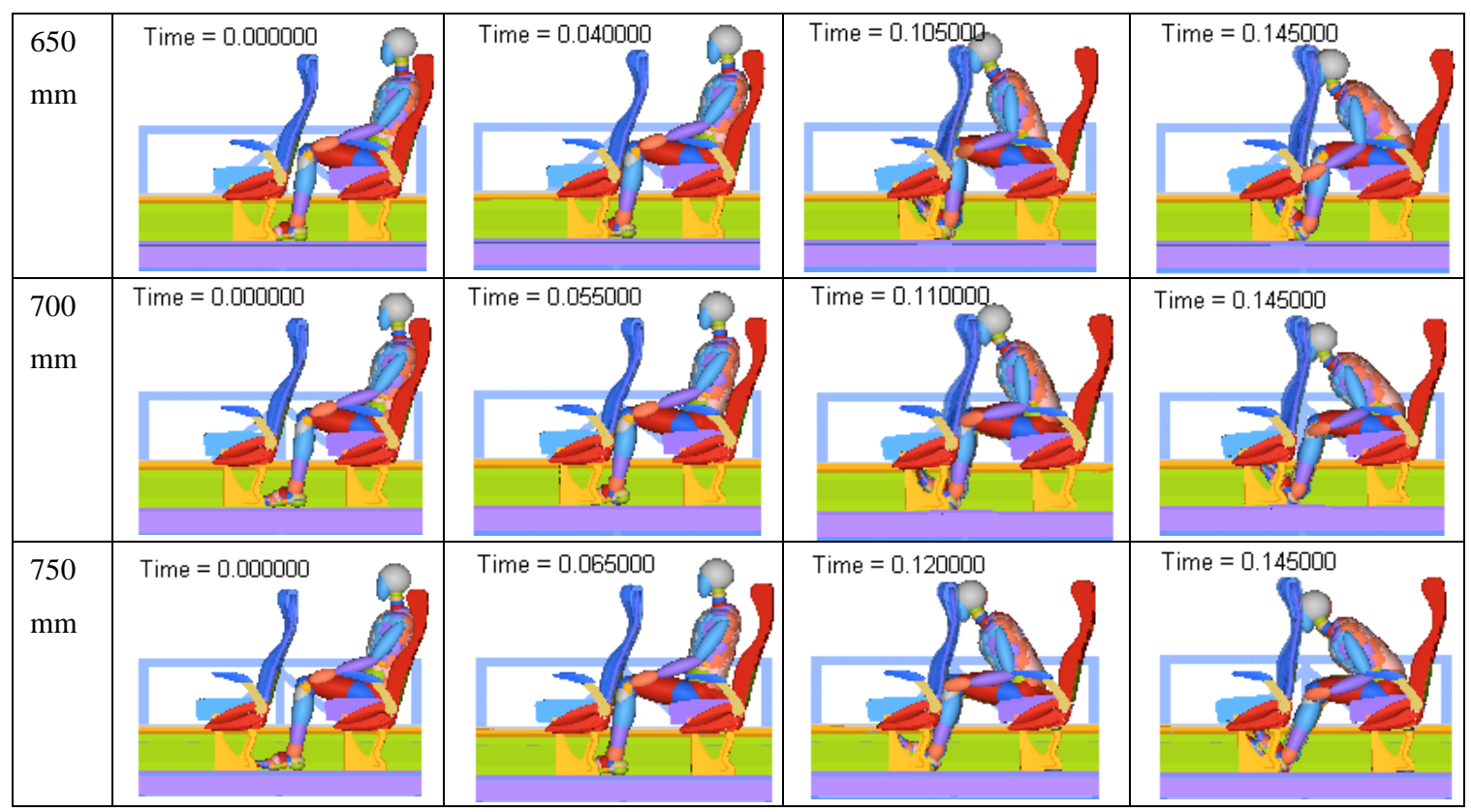




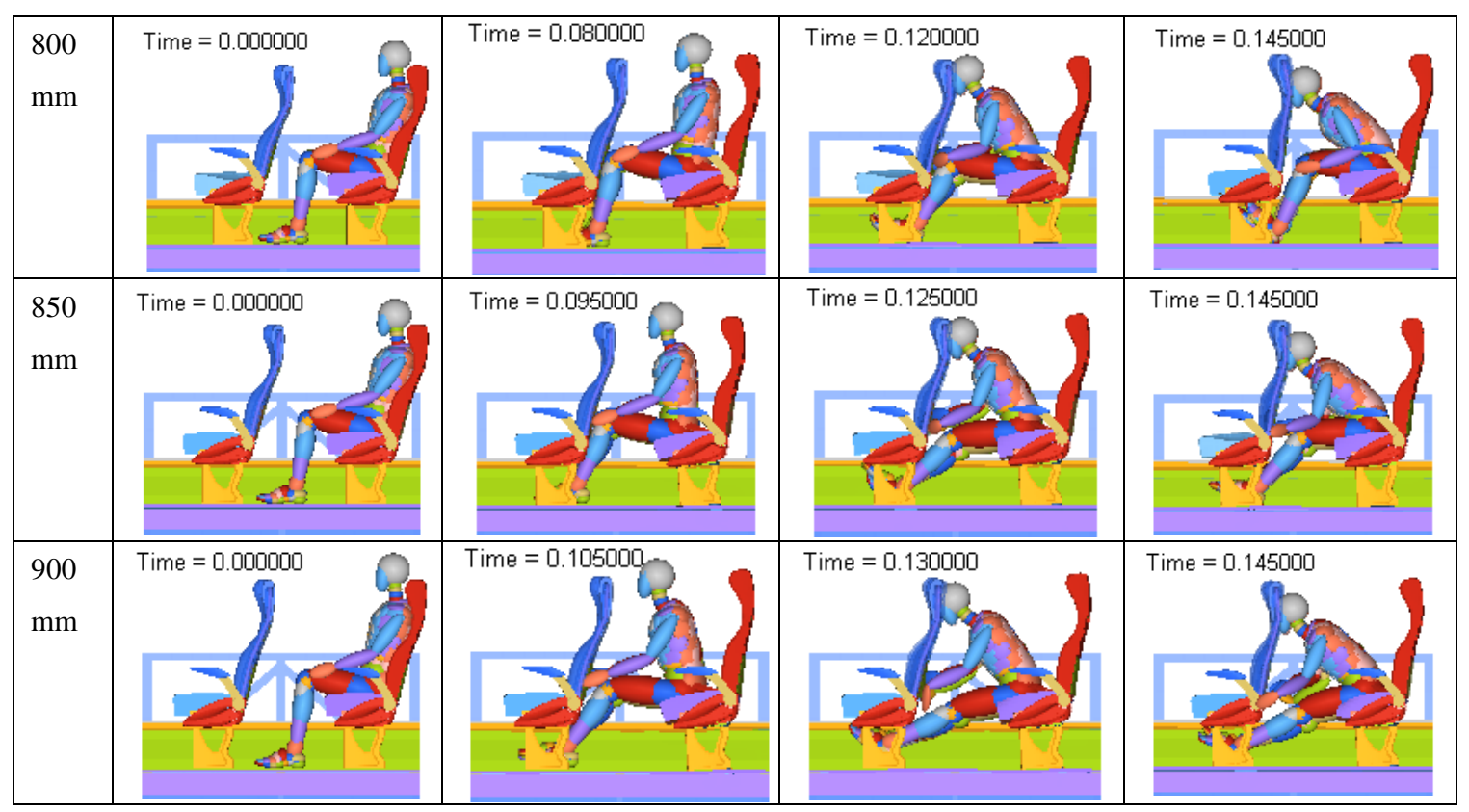

Figure 7: Dummy kinematics with different seat pitches from 650 to $900 \mathrm{~mm}$

As shown in Figure 8 ( $a$ and $b$ ), the range of HIC, ThAC and FAC values of the left and right femurs are 291 to $423,15 \mathrm{~g}$ to $19 \mathrm{~g}$ and $0.5 \mathrm{kN}$ to $2.4 \mathrm{kN}$, respectively. These parameters are the main assessment criteria of occupant injury in ECE R80. Compared with the corresponding limit values of $500,30 \mathrm{~g}$ and $10 \mathrm{kN}$ all of them meet the assessment requirements and have a degree of margin. The tibia index is not considered in the ECE R80 assessment. In this study, results show that TI ranges from 0.43 to 0.83 which is less than the threshold of 1.3 for all test scenarios.

In order to evaluate the occupant injury risk comprehensively, the head acceleration, neck bending moment and $\mathrm{N}_{\mathrm{ij}}$ are evaluated in addition to the evaluation criteria specified by ECE R80.

The acceleration curve of the occupant head is shown in Figure 8 (c). When the seat pitch is $650 \mathrm{~mm}$ to $850 \mathrm{~mm}$, the peak head acceleration is higher than $80 \mathrm{~g}$. Critically, when the 
seat pitch is $750 \mathrm{~mm}$, head peak acceleration over $80 \mathrm{~g}$ lasts close to $3 \mathrm{~ms}$. When the distance reaches $900 \mathrm{~mm}$, the head peak acceleration is only $59 \mathrm{~g}$. Considering that the bus seat usually covers the metal skeleton with foam, when the head collides with seat, the head contact point and contact angle influence the severity of collision under different seat pitch. As shown in Figure 9 and Figure 8 (c), when the pitch is $650 \mathrm{~mm}$ to $850 \mathrm{~mm}$, the head will contact the metal frame of the front seat, resulting in a higher acceleration peak and longer duration. When the distance is $900 \mathrm{~mm}$, the head of the dummy contacts the frame of the seat indirectly, and mainly collides with the foam, resulting in relatively low overall acceleration.

As shown in Figure $8(\mathrm{~d})$, the range of $\mathrm{N}_{\mathrm{ij}}$ and neck bending moment are 0.43 to 0.56 and $52 \mathrm{Nm}$ to $66 \mathrm{Nm}$ respectively. ECE R80 does not require the assessment of $\mathrm{N}_{\mathrm{ij}}$ and neck bending moment. Compared with the UN R94 reference value, $\mathrm{N}_{\mathrm{ij}}$ is far less than 1.0. However, the neck bending moment is higher overall, compared with the FMVSS208 limit value of $57 \mathrm{Nm}$, with most of the scenarios beyond the limit value. The above two parameters, $\mathrm{N}_{\mathrm{ij}}$ and neck bending moment, are the most common indicators to evaluate neck injury. In spite of the low overall $\mathrm{N}_{\mathrm{ij}}$ value, most of the neck bending moments exceed the limits. The risk of occupant neck injury in front collision should therefore not be ignored. 

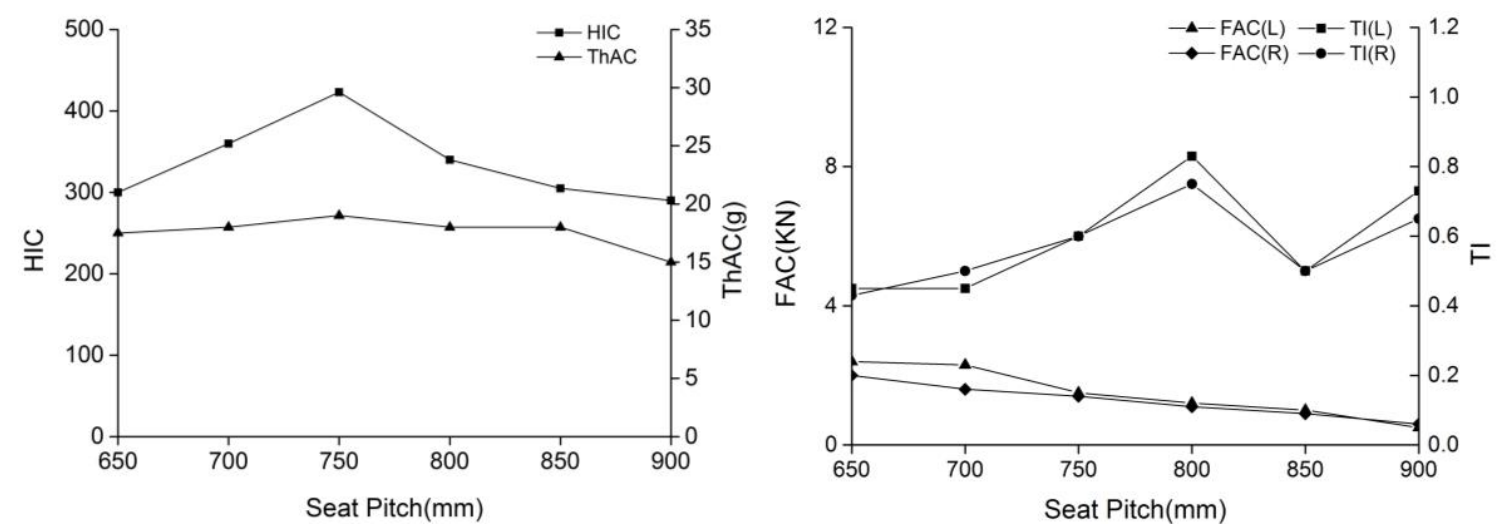

(a) Effect of seat pitch on HIC and ThAC

(b) Effect of seat pitch on FAC and TI
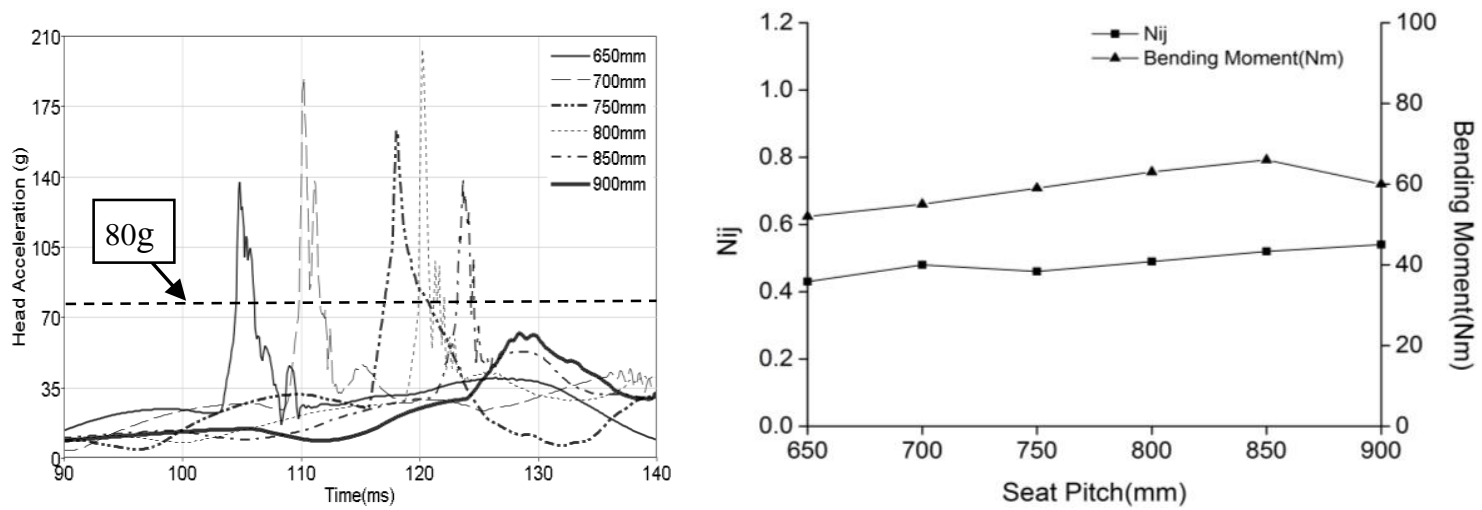

(c) Effect of seat pitch on Head acceleration (d) Effect of seat pitch on $\mathrm{N}_{\mathrm{ij}}$ and neck bending moment

Figure 8: Injury value of the dummy under various seat pitches showing that seat pitch influences the value of HIC, ThAC, FAC, TI, Head acceleration, $\mathrm{N}_{\mathrm{ij}}$ and neck bending moment.

\begin{tabular}{|c|c|c|}
\hline $650 \mathrm{~mm}$ & $700 \mathrm{~mm}$ & $750 \mathrm{~mm}$ \\
\hline & & \\
\hline
\end{tabular}




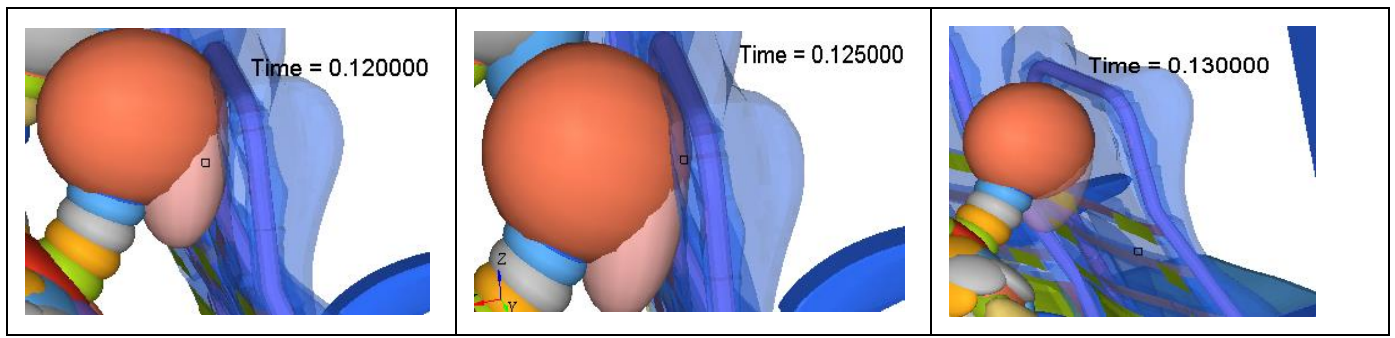

Figure 9: Detailed contact characteristics between head and seat back demonstrating the contact time and contact position when the occupant head collides with seat back.

It is worth pointing out that although the HIC values are all within the ECE R80 limit of 500 , the head acceleration peak is higher as a whole, the duration is longer, and there is a greater risk of head injury. Although the head acceleration peak value is relatively low when the pitch is $900 \mathrm{~mm}$, the dummy neck bending moment is still higher than the threshold of $57 \mathrm{Nm}$.

\subsection{Influence of Height Difference on Kinematics and Injury Characteristics}

These tests were carried out at the standard pitch of $750 \mathrm{~mm}$, while changing the seat height difference. As shown in Figure 10, due to different height between the front and rear seats, the contact positions of the tibia, knee, head and front seat change greatly. When the front seat is high $(\mathrm{A}=-100 \mathrm{~mm}$ and $-200 \mathrm{~mm})$, the knees collides with the lower seat frame. The torso rotates about the pelvic axis. Subsequently, the head hits the upper of the seat back and slide continuous, resulting in extreme neck hyper flexion. When the front seat is lower $(A=0 \mathrm{~mm}, 100 \mathrm{~mm}$ and $200 \mathrm{~mm})$, the lower limb collides with the seat foam or softer part. Similarly, the head hits the upper seat back. However, the slippage with the seat back is not obvious, and the tendency of the neck to rotate backward is 
relatively small. When $\mathrm{A}=200 \mathrm{~mm}$, the tendency for the head to hit the seat top increases, which may result in higher concussion since it may collide with the hard seat frame. It is also worth noting that at $\mathrm{A}=0 \mathrm{~mm}$ and $100 \mathrm{~mm}$ the tibia is exposed to bending load created through contact with the front seat lower around the centre of the shin.

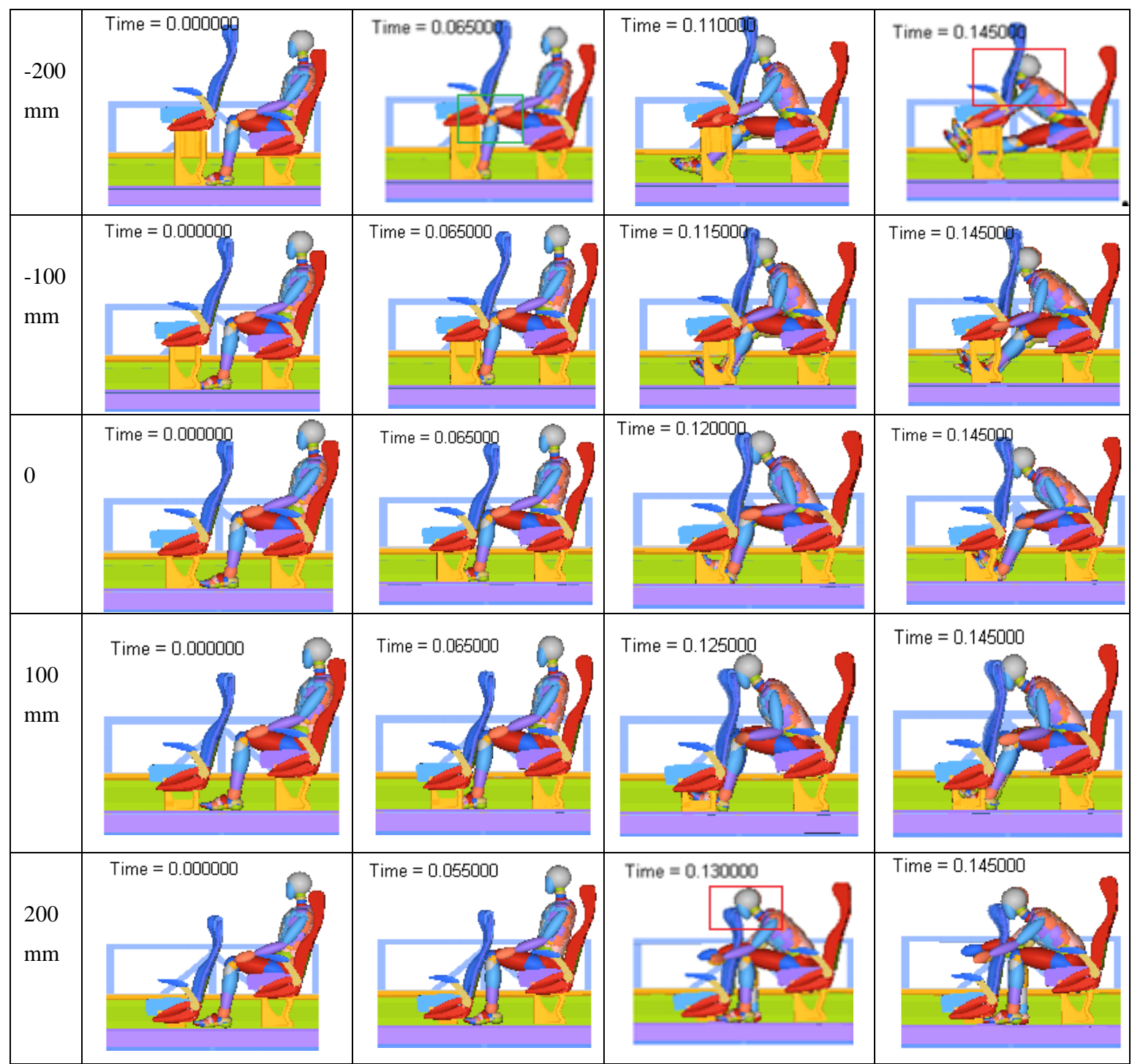

Figure 10: Dummy kinematics under various height differences from -200 to 200mm As shown in Figure $11(a, b)$, there is no significant difference in HIC values when height difference is $-200 \mathrm{~mm}$ to $100 \mathrm{~mm}$. However, the HIC value increases to 660 exceeding the 
ECE R80 threshold of 500 when the height difference reaches $200 \mathrm{~mm}$. The change of seat height difference had no effect on the ThAC, ranging from $17.5 \mathrm{~g}$ to $19.1 \mathrm{~g}$. FAC values on both femurs are overall small, and decrease with reducing height of the front seat. The reason is that when the front seat position is higher, occupant knees hit the front seat frame. However, as the front seat height reduces, the knees mainly collide with the foam or softer area, and the loading decreases significantly. The tibia index resembles FAC, showing a similar trend.

The head acceleration curve is shown in Figure 11 (c). For all the scenarios, the head has a higher acceleration peak than the prescribed $80 \mathrm{~g}$, and most last more than $3 \mathrm{~ms}$ above $80 \mathrm{~g}$. When the front seat is higher $(\mathrm{A}=-100 \mathrm{~mm}$ and $-200 \mathrm{~mm})$, although the peak value of acceleration is relatively low, the duration of over $80 \mathrm{~g}$ is about $5 \mathrm{~ms}$. When the front seat is lower, the head has a very high acceleration peak. The graph shows that it may be prone to multiple collisions.

The neck injury index is shown in Figure 11 (d). When the height difference is $-100 \mathrm{~mm}$ to $100 \mathrm{~mm}$, the neck bending moment and $\mathrm{N}_{\mathrm{ij}}$ have no obvious changes. The neck bending moment is maintained at $62 \mathrm{Nm}$ exceeding the limit range of $57 \mathrm{Nm}$. However, $\mathrm{Nij}$ remains at 0.50 . It is worth noting that when the height difference reaches $-200 \mathrm{~mm}$, the neck bending moment is about $130 \mathrm{Nm}$, twice as much as limit value. $\mathrm{N}_{\mathrm{ij}}$ reaches to 1.38 , $38 \%$ higher than the limit value. When the height difference is $200 \mathrm{~mm}$, the neck bending moment and $\mathrm{N}_{\mathrm{ij}}$ falls to $39 \mathrm{Nm}$ and 0.56 respectively, which meet the requirements of the limit value. 

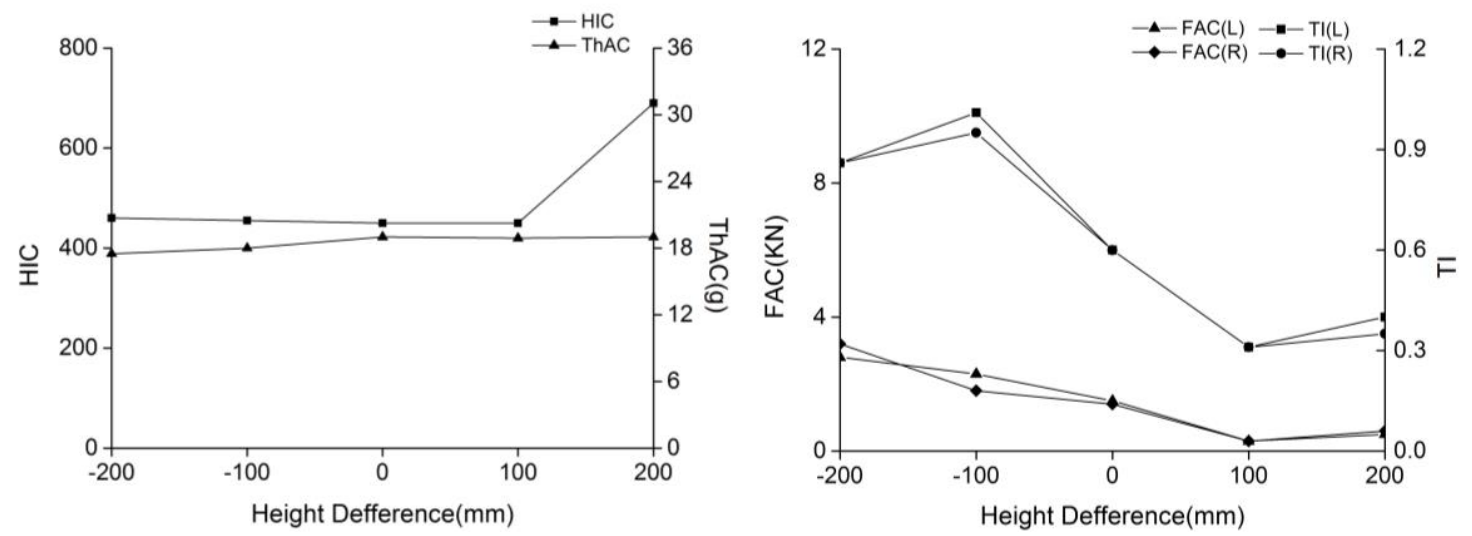

(a) Effect of height difference on HIC and ThAC (b)

(b) Effect of height difference on FAC and TI
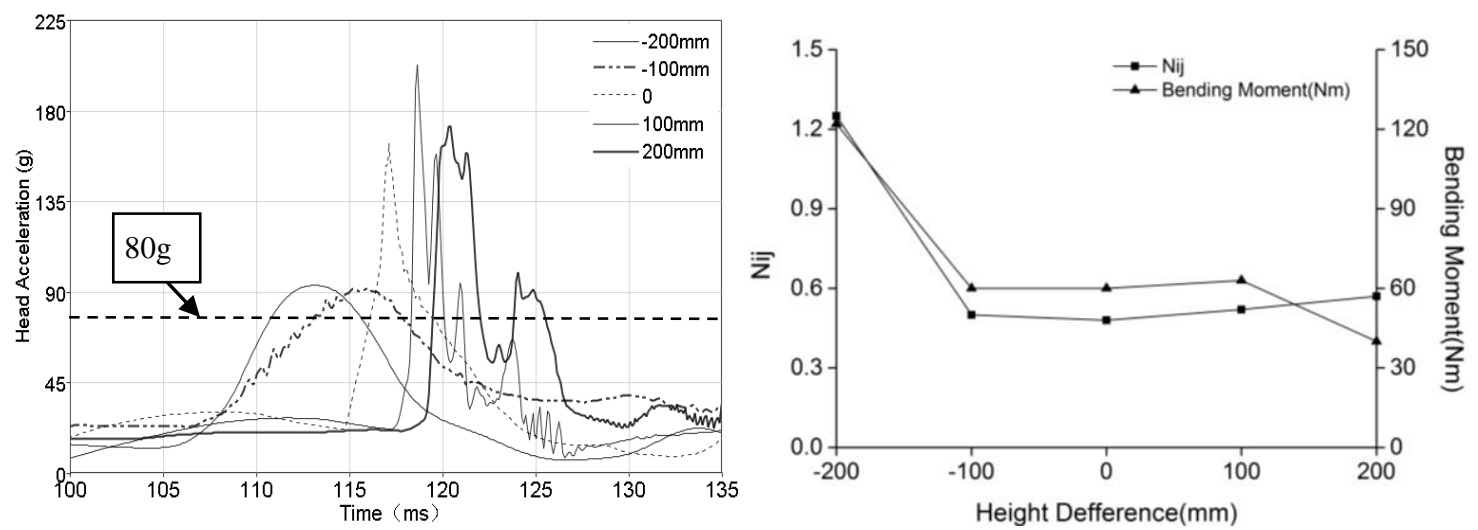

(c) Effect of height difference on head acceleration (d) Effect of height difference on $\mathrm{N}_{\mathrm{ij}}$ and neck bending moment

Figure 11: Injury value of the dummy under various height differences importantly showing that height difference influences the value of HIC, ThAC, FAC, TI, Head acceleration, $\mathrm{N}_{\mathrm{ij}}$ and neck bending moment.

When both the HIC value and head acceleration are considered, results show that no matter how the height of the front and rear seats is distributed, the peak head acceleration of the occupant is highest for the standard $750 \mathrm{~mm}$ pitch. Importantly, this indicates that the existing safety standards have limitations for only applying HIC value as a means to evaluate head protection. Although the layout where the front seat is higher than the rear seat is not common, when the height difference is over $-100 \mathrm{~mm}, \mathrm{~N}_{\mathrm{ij}}$ and neck moment 
can cause very severe injuries due to the relative slippage between head and front seat back surface a long duration. In bus construction, the most common configuration is where the front seat is lower than the subsequent rear seat. When the height difference is over $100 \mathrm{~mm}$, the collision between the head and the front seat frame produces head acceleration for relatively long duration and results in relatively high HIC value.

\subsection{Influence of Back Inclination Angle on Kinematics and Injury}

\section{Characteristics}

Because of the space limitation, the adjustment of the seat back inclination angle of the rear seats will significantly affect the head movement space as shown in Figure 12. When the back inclination angle is small, the head movement space is relatively small. The front seat terminates the forward motion of the head, thereby reducing its speed, while the neck bends hyper flexes, especially at $95^{\circ}$. As the back inclination angle increases, the tendency for the neck to flex reduces. This is because the contact angle between the head and front seat back creates more of a compressive load rather than bending load.

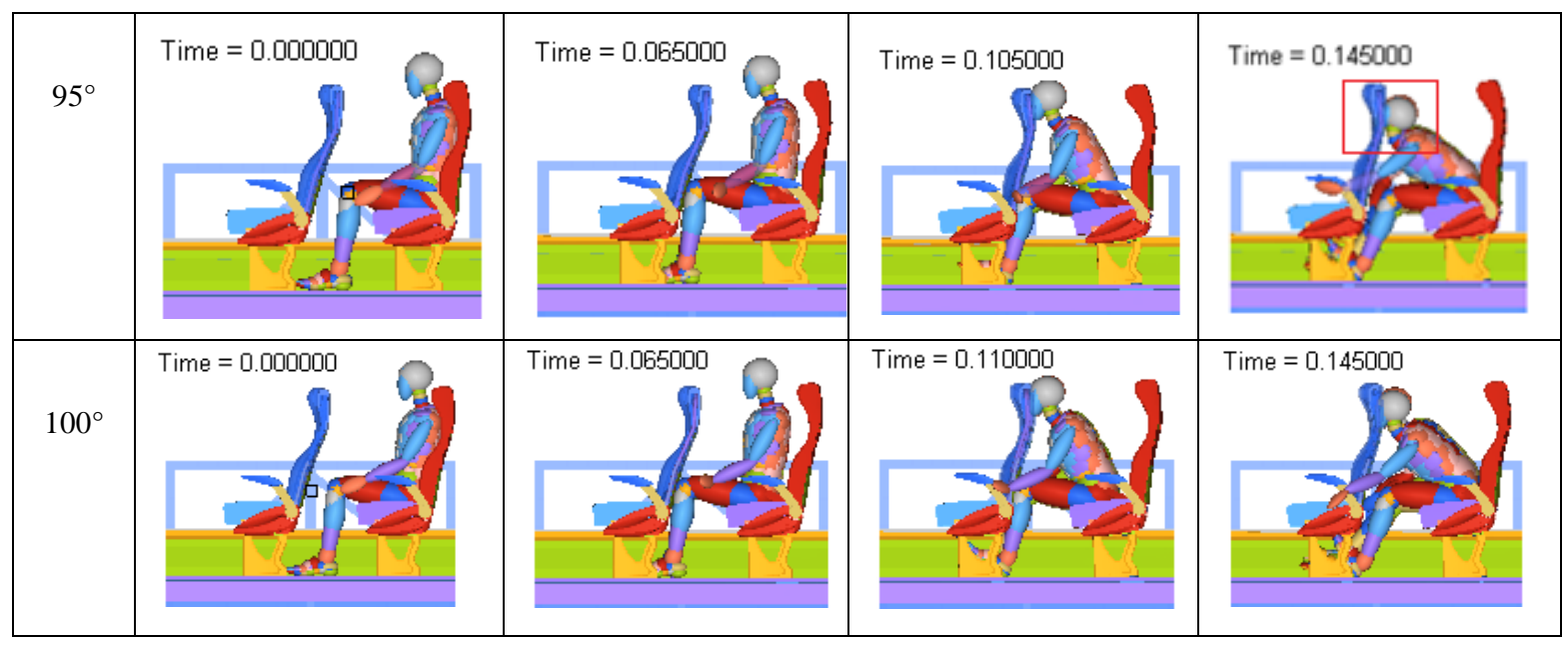




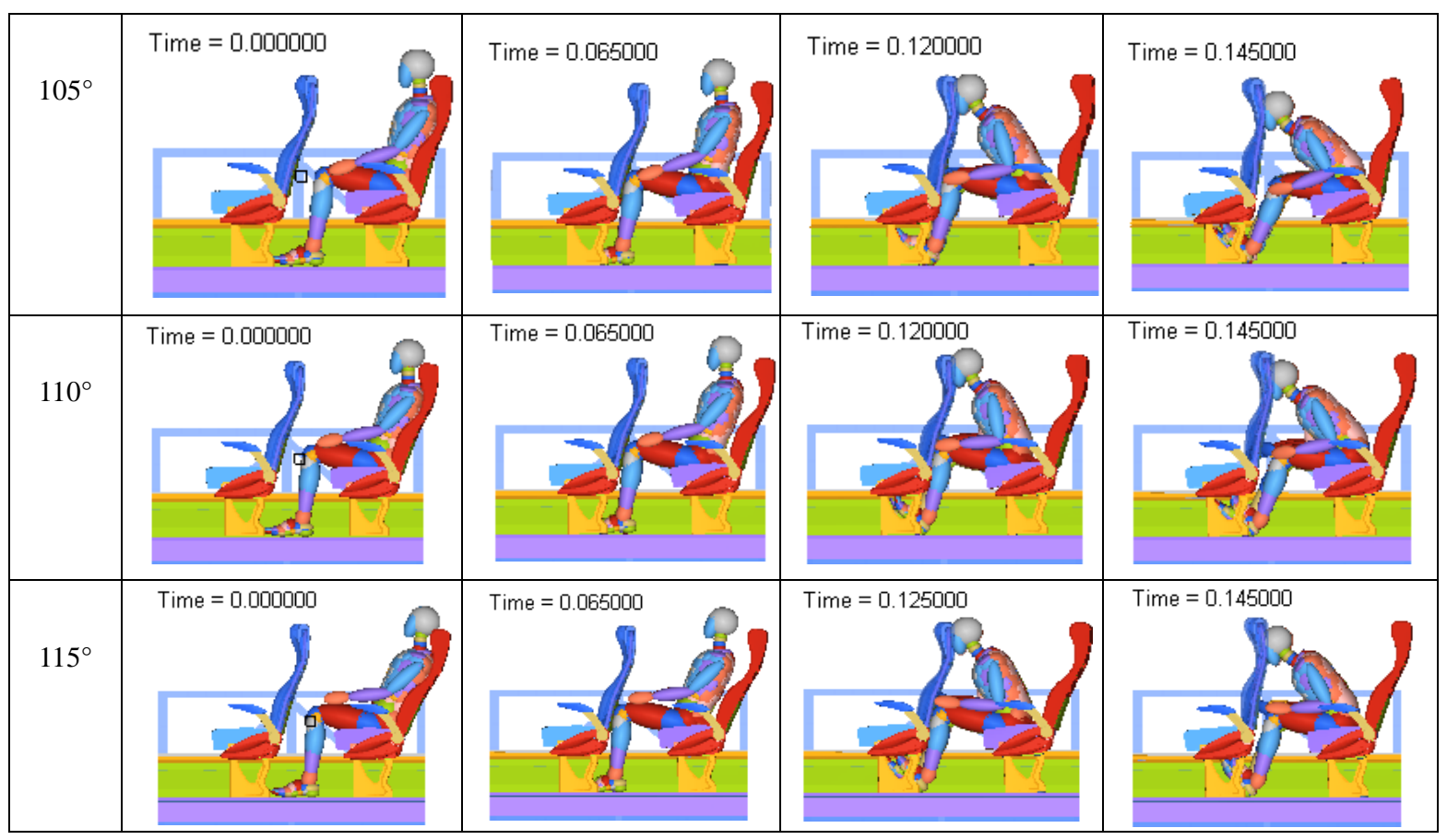

Figure 12: Dummy kinematics under various back inclination angle from $95^{\circ}$ to $115^{\circ}$ showing the effect on head movement space.

Figure 3 ( $a$ and b) shows that the occupant HIC, ThAC and TI values were 277 to 423 , $19 \mathrm{~g}$ to $21 \mathrm{~g}$ and $0.72 \mathrm{kN}$ to $1.65 \mathrm{kN}$, respectively. All these meet the requirements of ECE R80 assessments. In all scenarios, there was no significant change in thorax and femur injury levels. This indicates that thorax and femur injuries are not sensitive to seat back angle.

As shown in Figure 13 (c), the neck bending moment decreases significantly with the increase of the seat back inclination angle, especially from $95^{\circ}$ to $100^{\circ}$. The neck bending moment is $94.6 \mathrm{Nm}$ at $95^{\circ}, 65.8 \%$ higher than the limit value. As the angle increases, the neck bending moment was decreased. When the back angle is $100^{\circ}$, the neck bending moment reduces to $63.7 \mathrm{Nm}$. 
As shown in Figure 13 (d), the head peak acceleration increases with the increase of the seat back inclination angle. The peak time lags behind because the impact time is late. When the seat back inclination angle is $95^{\circ}$ and $100^{\circ}$, the head peak acceleration is relatively small. However, when the back angle is over $105^{\circ}$, the head peak acceleration rises rapidly.

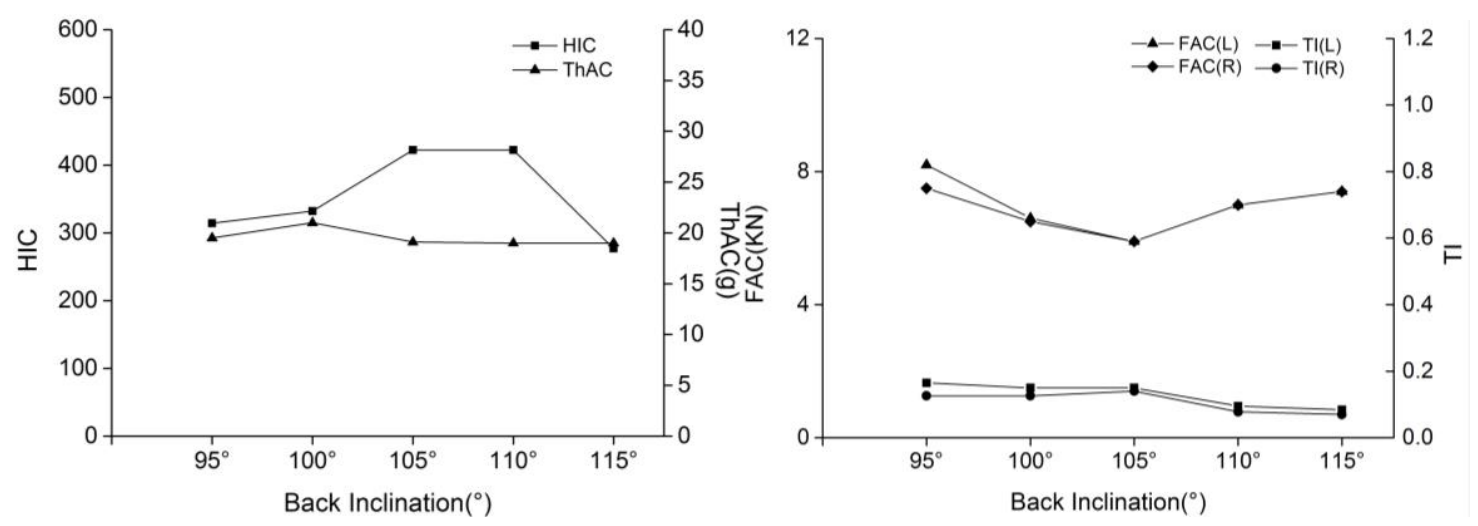

(a) Effect of back inclination on HIC and ThAC (b) Effect of back inclination on FAC and

TI
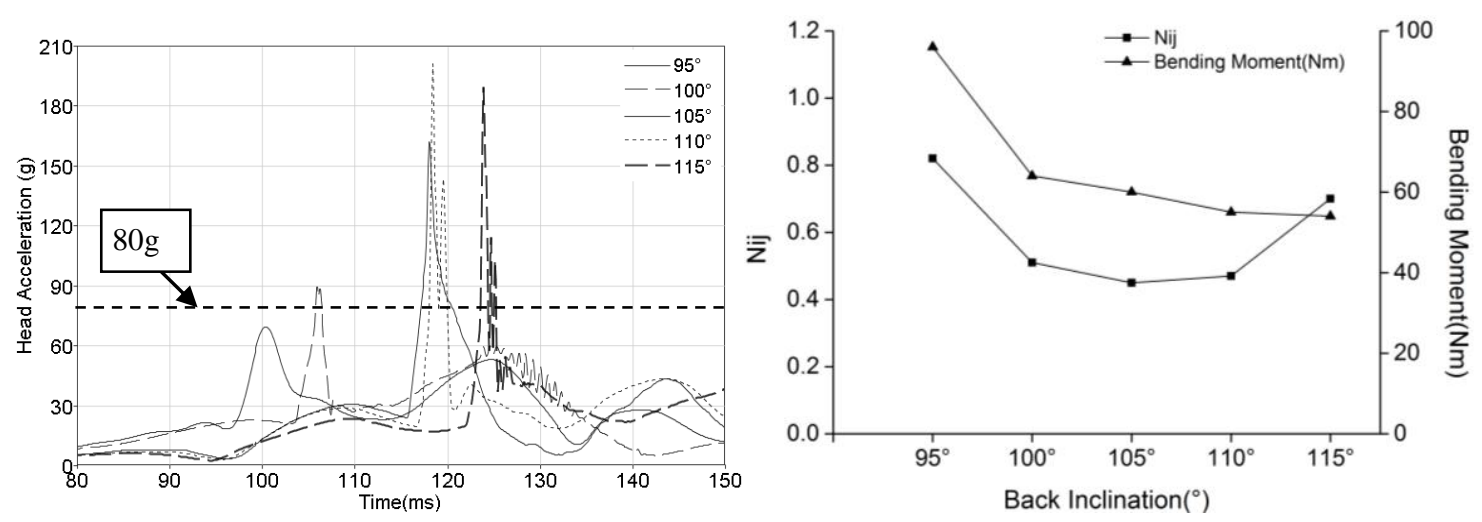

(c) Effect of back inclination on head acceleration (d) Effect of back inclination on $\mathrm{N}_{\mathrm{ij}}$ and neck bending moment

Figure 13: Injury value of the dummy under various back inclination angle showing that back inclination angle influences the value of HIC, ThAC, FAC, TI, Head acceleration, $\mathrm{N}_{\mathrm{ij}}$ and neck bending moment. 
When the seat back inclination angle is smaller, the distance between head and front seat is smaller, the collision time is earlier, and the peak acceleration is smaller. With the increase of back angle, the head peak acceleration increases gradually, but the duration of collision becomes shorter. It is worth noting that the higher the angle, the higher is the initial gap between the head and the front seat. With the higher gap, the head traverses a longer distance before secondary collision occurs. Inevitably, the longer distance allows for the impact velocity to increase, resulting in a higher velocity change (and deceleration) on impact.

\section{Discussion}

In this study, occupant injury distribution characteristics were determined under different scenarios. These were compared with ECE R80 injury evaluation indices, which include the role of lap belt. Although occupant HIC value does not exceed the limit value of 500 under most conditions, the head acceleration was found to be above $80 \mathrm{~g}$, with relatively a long duration. This shows that the risk of head injury is still high. Therefore, applying HIC as the only assessment criteria is not adequate to ensure the safety of the head. In the numerical simulation, in most cases the neck moment value was found to be higher than $57 \mathrm{Nm}$. The main reason is that lap belt cannot effectively constrain the parts above the hip. This leads to large head displacement and neck bending moment caused by relative slippage between the head and the back of the front seat. The above further shows that for the current ECE R80 to be sufficient, the head acceleration (Clip3ms) and neck bending 
moment should be added as injury criteria to effectively protect bus occupants as those also accounts for a mortal injury, this further explains that although buses well fulfilled the standard of ECE R80, whereas mass fatalities per incidence still exists worldwide.

In the bus seat layout design, height difference between the front row seats and the rear seats is more likely to cause significant occupant injury. Rear occupant's head acceleration, $\mathrm{N}_{\mathrm{ij}}$, neck bending moment and femur loading present higher risk of injury in varying degrees, especially above $-100 \mathrm{~mm}$, when the front seats are higher than the rear seats. When the front seat is lower than the rear seat, the risk of neck and femur injuries of the rear occupants is relative low. This is despite the collision position between rear occupant and front seat changing. However, the HIC value would exceed the limit value. Therefore, as a general design philosophy, in the seat layout the front seats should not be higher than the rear seats.

ECE R80 mainly considers integrity of structure and safety of occupant in bus seat safety design. Li $\mathrm{Z}$ et al [12] proposed to reduce the risk of occupant head and neck injury by optimizing the front seat joint moment and rotation angle. They found that when the joint moment increases, neck injury risks will be higher, and when the joint moment decreases, neck injury risk will be lower. But considering that utilization rate of seat belt is not high enough in the actual use, the joint moment is too low to increase the occupant risk of forward ejection. It is therefore suggested to add foam, and to use aluminium honeycomb material, which is an elastic material with lower yield strength. The lower yield strength 
can ensure that the occupant can have more buffer space when hitting the front seat, thereby reducing the degree of neck backward.

The simulation results in this study show that when the head of occupant contacts with the front seat back in the frontal collision, the neck of the occupant has the tendency of rotating backward. This is despite the use of a lap belt. In fact, experimental results showed that an occupant who is not belted does not tend to experience similar kinematics as long as the front seat meets strength requirements. The best form of protection would be installation of lap/shoulder belt similar to cars. At present, the buses are equipped with lap belt in addition to the occupants sitting in the cab. There is an additional requirement for the first row of passengers to have a lap/shoulder belt. Although the lap belt can act better on the occupant's pelvis and limit the occupant movement, the head can easily collide with the front seat.

The use of lap/shoulder belt cannot only limit occupant movement, but also protect the occupant head. At the same time, the design parameters of the seat belt in occupant restraint system include the webbing stiffness, the fixed point position and the preload parameters, and the optimization of these parameters can reduce the injury risk and improve the survival probability.

\section{Conclusions and Recommendations}

In this paper results of experimental tests based on ECE R80, and corresponding virtual parametric tests have been presented. The variables included seat pitch, height difference 
and back inclination angle. The results show that secondary collision with the front seat back can cause severe head and neck injuries. This is irrespective of whether the occupant uses a restraint (belt), or not. This is the condition where the unrestrained occupant collides with the front seat back which is high enough to prevent forward ejection.

Both sled and virtual tests revealed that although the lap belt can restrict the movement of the pelvis and lower limbs better, the collision and relative slippage between the head and the front seat back can still cause the high neck bending moment. The parametric virtual crash tests further showed that the seat pitch, height and inclination angle influence torso, neck and head kinematics. This subsequently determines the injury mechanism and ultimate injury severity.

For all values of seat pitch, the head acceleration was greater than $80 \mathrm{~g}$, with varying duration above this threshold. The neck bending moment was greater than the $57 \mathrm{Nm}$, though marginally. The analysis of seat height difference shows that when the rear seat is higher than the front, only the head is at high risk of severe injuries. On the other hand, when the rear seat is lower, the neck and tibia have a high risk of severe injuries. When there is no height difference between the front and rear seats, literally all the criteria are met except for head acceleration which was above the $80 \mathrm{~g}$ threshold. Ideally, therefore, an idea design should imply all seats at the same level. By design, however, the bus floor implies that the rear seat is nearly always higher than the front seat. 
Parametric study of the change in angle of inclination showed that a higher angle $\left(105^{\circ}\right.$ to $115^{\circ}$ ) pose a high risk of head injuries based on maximum acceleration above $80 \mathrm{~g}$. The other body parts are at low risk. On the other hand, when the angle is low $\left(95^{\circ}\right)$, all the other body parts are at low risk of severe injuries, while the neck has a very high injury risk potential.

The above deductions show that these parameters should therefore be design-specified to optimal values that minimize such injuries.

From the results of this investigation, recommendations are being made on the development of government policy and industry standards aimed at improving the occupant injury risk in the event of a frontal crash:

1) Head injury assessment without considering head acceleration puts the head at high risk (use of HIC may not be adequate). It is suggested that Clip3ms, TI and neck bending moment should be considered into relevant regulations of occupant injury criteria.

2) In the seat layout, the front row should be designed lower than the subsequent back row. However, large height differences should be avoided as they are likely to cause high occupant injury risk.

3) To fit lap/shoulder belt as a standard; lap/shoulder seat belt can effectively limit the movement of occupant and protect the head from impacts experienced when an occupant is either not using a belt at all or using a lap belt only.

4) To review the types of materials used in the construction of bus seats. For 
example, increase foam and use honeycomb aluminium material in the seat construction to provide more buffer space and reduce the degree of neck rotation.

Acknowledgments: This work was supported by the National Natural Science Foundation of China under Grant 51505403 and 51605407; 2011 Program of Bus and Specialty Vehicle Research\& Design Collaborative Innovation Centre in Fujian Province under Grant 2016AYF004; and the National High End Expert programme under Grant GDT20153600065.

\section{References}

[1] Ren Baokuan, Liu Rudi, Li Xiaoxia, et al. The Safety Technology Research Progress of Domestic Buses [J]. Journal of East China Jiaotong University. 2013; 10 (1): $81-86$.

[2] Wang Xin, Yan Changzheng, Qin Zhenyuan, et al. Study on Bus Frontal Crash Standards [J]. Communications Standardization. 2011; 8: 6-10.

[3] ZHANG Zhixin, XIAO Shoune, YANG Guangwu. research on collision safety of high-speed train crews \&passenger [J]. Journal of the China railway society. 2013, 35(10): 24-32.

[4] Mitsuishi H, Sukegawa Y, Okano S, et al. Frontal Collision Safety of Bus Passengers in Japan[J]. 2003.

[5] Washington, DC: NHTSA, US Department of Transportation. 2015. DOT HS 811 793.

[6] United Nations Economic Commission for Europe (UNECE), 1998. ECE R80: uniform provisions concerning the approval of seats of large passenger vehicles and of these vehicles with regard to the strength of the seats and their anchorages.

[7] National Highway Traffic Safety Administration (NHTSA), 1998b. FMVSS 207: seating system. 
[8] General Administration of Quality Supervision, Inspection and Quarantine of the People's Republic of China (AQSIQ) \& Standardization Administration of the People's Republic of China (SAC), 2012a. GB13057-2014: the strength of seats and their anchorages of passenger vehicles.

[9] Páez J, Furones A, Aparicio F, et al. Spanish Frontal Accidents of Buses \& Coaches. Injury Mechanism Analysis [J]. Procedia - Social and Behavioral Sciences. 2014; 160: 314-322.

[10] TOMINAGA SHIGERU, NISHIMOTO TETSUYA, KIKUCHI ATSUSHI. Analysis of Thoracic and Abdominal Injury of Belted Occupant's in Frontal Impact Based on In-depth Accident Sampling Data[J]. International Journal of Automotive Engineering. 2013; 44: 1073-1078.

[11] Mayrhofer E, Geigl B C, Steffan H. Evaluation of the effectiveness of a bus and coach seat during rear end impact by means of sled tests $[\mathrm{J}]$. International Journal of Crashworthiness. 2003; 8 (3): 255-267.

[12] Li Z, Ge H, Zhang J, et al. The necessity of evaluating child neck injury in frontal collision of school bus for transportation safety [J]. Safety Science. 2015; 62 (1): 441-449.

[13] L Martínez, T Vicente, A García, et al. Analysis of Coaches Rows Seats Distance Influence on the Passengers Comfort and Safety [J]. University Research for Automobile Research, Polytechnic University of Madrid. 2009; 09-0197: 1-13.

[14] Matsika E, Peng Q.. Crash safety of a typical bay table in a railway vehicle. Transport Problems. International Scientific Journal. Volume 10 Special Edition.

[15] Matsika E, Chirwa, E.C., Peng Q.. Kinematics and injury risk of a wheelchair occupant in a railway vehicle crash. International Journal of Crashworthiness.2014; 9 (5): 446-456(11). 
[16] Matsika, E., Chirwa, E. C., Peng, Q., Myler, P. and Nowpada, S. (2011): Wheelchair Occupant Kinematics During a Rail Carriage Crash. International Journal of Crashworthiness. 2011; 16 (5): 487-500.

[17] Gadd C W. Criteria for injury potential [J]. Impact Acceleration Stress Symposium,National Academy of Science,Washington DC,1961, National Research Council Publication No.977. Pages 141-144.

[18] National Highway Traffic Safety Administration (NHTSA), 1998d. FMVSS 208: occupant crash protection.

[19] United Nations Economic Commission for Europe (UNECE), 1998. UN R94: uniform provisions concerning the approval of vehicles with regard to the protection of the occupants in the event of a frontal collision.

[20] Ministry of Industry and Information Technology of the People's Republic of China. QC/T 633-2000: The Seats of Passenger Vehicles. 